\section{Spread of mcr-1-Driven Colistin Resistance on Hospital Surfaces, Italy}

\section{Elisabetta Caselli, Maria D’Accolti, Irene Soffritti, Micol Piffanelli, Sante Mazzacane}

Author affiliation: Università Degli Studi di Ferrara, Ferrara, Italy

DOI: https://doi.org/10.3201/eid2409.171386

Plasmid-mediated colistin resistance driven by the mcr-1 gene is of great clinical concern. Its diffusion in the hospital environment is unknown. We detected mcr-1-driven resistance in $8.3 \%$ of Enterobacteriaceae isolates from hospital surfaces in Italy, which might represent a reservoir of threatening nosocomial pathogens.

$\mathrm{T}$ he rapid and continuous growth of drug resistances is of global concern and one of the most severe threats for human health. Among those detected in recent years, a plasmid-mediated colistin resistance, driven by the $\mathrm{mcr}$ 1 gene (1), represents a serious clinical concern because colistin was considered a last-resort drug against multidrugresistant (MDR) gram-negative bacteria.

Since its original isolation in an Escherichia coli strain in China in 2016, the $\mathrm{mcr}-1$ gene has been detected almost globally in $\approx 10 \%$ of animal isolates (2) and in $0.1 \%-2 \%$ of human isolates (3), suggesting that this plasmid-mediated resistance spread efficiently from animals (where colistin has been used for years as a therapeutic drug or food supplement) to humans through horizontal gene transfer. Furthermore, the mcr-1 gene was found in different gramnegative bacteria, including Klebsiella pneumoniae, Enterobacter, Salmonella $(1,4,5)$, and recently Citrobacter (6). The emergence of $m c r-1$ in clinical Enterobacteriaceae isolates appears particularly alarming because it frequently occurs in MDR strains, further limiting current treatment options for lethal infections sustained by carbapenem-resistant Enterobacteriaceae.
In Italy, $m c r$-1-driven colistin resistance was first reported in an E. coli strain in 2016 (7). However, colistin resistance already had been reported previously in carbapenem-resistant Enterobacteriaceae from different peripheral laboratories in Italy $(8)$.

The $m c r-1$ gene has been detected in infected persons, but its epidemiology is poorly described, and data are lacking about its presence in the microbial population that persistently contaminates hospital environments. Surface contamination is known to contribute to the onset of healthcare-associated infections, which are often sustained by MDR or even pan-drug-resistant strains. Thus, based on the need for information about this aspect, we aimed to determine the diffusion of $m c r-1$-driven colistin resistance in the hospital environment.

We searched for the presence of $m c r-1$ gene in our library of 300 Enterobacteriaceae samples collected from the surfaces of 8 hospitals in Italy during 2016-2017. Surface samples were collected from 3 points in hospital rooms (floor, bed footboard, and sink) as previously described (9), then grown in MacConkey broth for $48 \mathrm{~h}$ at $37^{\circ} \mathrm{C}$ to amplify the Enterobacteriaceae population. An aliquot of grown bacteria was frozen in $50 \%$ sterile glycerol for subsequent identification and functional studies. The remaining bacterial suspension was used for total DNA extraction (UCP-Pathogen Mini Kit; QIAGEN, Hilden, Germany) and analyzed for $m c r-1$ gene presence by nested PCR. We conducted first-round amplifications as previously described (1); nested PCR amplification was carried out using the following primers and conditions: CLRn-F (5'-AAA CCT ATC CCA TCG CGG AC-3') and CLRn-R (5'-CCG CGC CCA TGA TTA ATA GC-3'), for 35 cycles at $57^{\circ} \mathrm{C}$, originating a 147-bp amplification product, subsequently confirmed by sequence analysis. Plasmid pBAD24::mcr-1 (3) was used as a positive control. We also conducted a universal panbacterial PCR as a control of DNA amplification (9). Whole-genome sequence and $m c r-1$ location were not analyzed here and might deserve future study.

Of 300 Enterobacteriaceae isolated from hospital surfaces, $25(8.3 \%)$ harbored the $m c r-1$ gene. All positive samples were culturally isolated on MacConkey agar plates.

\begin{tabular}{|c|c|c|c|c|c|c|c|c|c|c|}
\hline \multirow[b]{2}{*}{ Bacteria } & \multirow{2}{*}{$\begin{array}{c}\text { No. } \\
\text { isolates }\end{array}$} & \multicolumn{9}{|c|}{ Drug-resistant isolates, \% (MIC, $\mathrm{mg} / \mathrm{L})$} \\
\hline & & $\mathrm{F}$ & AK & ATM & TZP & $\mathrm{C}$ & SXT & NET & CTX & Col-R \\
\hline Acinetobacter Iwoffii & 4 & 50 & 25 & 50 & 50 & 25 & 50 & 25 & 25 & $7(4-8)$ \\
\hline Citrobacter freundii & 1 & 0 & 0 & 0 & 0 & 100 & 0 & 0 & 0 & 4 \\
\hline Enterobacter cloacae & 3 & 100 & 100 & 33.3 & 100 & 33.3 & 33.3 & 100 & 33.3 & 16 \\
\hline Enterobacter agglomerans & 3 & 100 & 0 & 0 & 100 & 0 & 0 & 100 & 0 & $5.3(4-8)$ \\
\hline Escherichia coli & 4 & 100 & 50 & 25 & 100 & 0 & 25 & 100 & 50 & $10(8-16)$ \\
\hline Klebsiella pneumoniae & 6 & 100 & 100 & 33.3 & 66.6 & 66.6 & 0 & 100 & 66.6 & $13.3(8-16)$ \\
\hline K. oxytoca & 2 & 100 & 100 & 0 & 0 & 0 & 0 & 100 & 0 & 16 \\
\hline Pseudomonas aeruginosa & 1 & 0 & 100 & 0 & 100 & 100 & 0 & 100 & 100 & 4 \\
\hline P. putida & 1 & 0 & 100 & 0 & 0 & 100 & 0 & 100 & 0 & 8 \\
\hline
\end{tabular}

*AK, amikacin $30 \mu \mathrm{g} ; \mathrm{ATM}$, aztreonam $30 \mu \mathrm{g} ; \mathrm{C}$, chloramphenicol $30 \mu \mathrm{g}$; Col-R, colistin resistant; CTX, cefotaxime $5 \mu \mathrm{g}$; F, nitrofurantoin $100 \mu \mathrm{g}$; NET, netilmicin $10 \mu \mathrm{g}$; SXT, trimethoprim/sulfamethoxazole $25 \mu \mathrm{g}$; TZP, piperacillin/tazobactam $36 \mu \mathrm{g}$. 
We identified presumptive positive isolates at the species level by biochemical typization (API-20E) and Vitek-2 system (BioMérieux, Florence, Italy) and tested them for drug susceptibility by disc diffusion (Entero1 Multodisc; Liofilchem, Teramo, Italy) and broth microdilution (SensiTest Colistin, Liofilchem).

Identification results indicated that different species harbored the $m c r-1$ gene, including $K$. pneumoniae, K. oxytoca, E. coli, Acinetobacter Iwoffii, Enterobacter cloacae, E. agglomerans, Citrobacter freundii, Pseudomonas aeruginosa, and P. putida (Table). These results suggest that this gene is silently spreading to many gram-negative bacteria responsible for infections in clinical settings.

All $m c r-1-$ carrying isolates were colistin resistant by microdilution test (MIC $4 \mathrm{mg} / \mathrm{L}$ to $>16 \mathrm{mg} / \mathrm{L}$ ). In addition, as judged by the results obtained by the disc-diffusion method, all colistin-resistant isolates were resistant to $\geq 2$ antimicrobial drugs among those effective against Enterobacteriaceae, exhibiting a MDR phenotype.

Our data show that mcr-1-carrying Enterobacteriaceae can be detected on hospital surfaces with higher frequency than in clinical isolates, indicating that this plasmid has the ability to spread, not only in vitro (1), in key human pathogens. Persistent surface contamination in hospitals might thus favor colistin resistance spread among gram-negative bacteria, perhaps helped by selective pressure exerted by some antiseptics (i.e., chlorhexidine) (10). Although this finding might represent a potential reservoir of threatening nosocomial pathogens and favor their diffusion in hospitalized patients, currently no specific monitoring exists to control it. Thus, we suggest that surveillance for $\mathrm{mcr}$-1-driven colistin resistance might include not only clinical samples but also environmental analyses and all clinically relevant gram-negative species to control and counteract the increase of untreatable infections.

\section{About the Author}

Dr. Caselli is a professor of microbiology and clinical microbiology at the Faculty of Medicine of the University of Ferrara. Her research interests include infectious diseases, microbiology, virology, molecular virology, antiviral immune response, autoimmunity, and healthcare-associated infections.

\section{References}

1. Liu YY, Wang Y, Walsh TR, Yi LX, Zhang R, Spencer J, et al. Emergence of plasmid-mediated colistin resistance mechanism MCR-1 in animals and human beings in China: a microbiological and molecular biological study. Lancet Infect Dis. 2016;16:161-8. http://dx.doi.org/10.1016/ S1473-3099(15)00424-7

2. Irrgang A, Roschanski N, Tenhagen BA, Grobbel M, Skladnikiewicz-Ziemer T, Thomas K, et al. Prevalence of $m c r-1$ in E. coli from livestock and food in Germany, 2010-2015. PLoS One. 2016;11:e0159863. http://dx.doi.org/10.1371/ journal.pone. 0159863

3. Ye H, Li Y, Li Z, Gao R, Zhang H, Wen R, et al. Diversified $m c r$-1-harbouring plasmid reservoirs confer resistance to colistin in human gut microbiota. MBio. 2016;7:e0177. http://dx.doi.org/10.1128/mBio.00177-16

4. Wong SC, Tse H, Chen JH, Cheng VC, Ho PL, Yuen KY. Colistin-resistant Enterobacteriaceae carrying the $\mathrm{mcr}$ - 1 gene among patients in Hong Kong. Emerg Infect Dis. 2016;22:1667-9. http://dx.doi.org/10.3201/eid2209.160091

5. Tse H, Yuen KY. Dissemination of the $m c r-1$ colistin resistance gene. Lancet Infect Dis. 2016;16:145-6. http://dx.doi.org/10.1016/ S1473-3099(15)00532-0

6. Li XP, Fang LX, Jiang P, Pan D, Xia J, Liao XP, et al. Emergence of the colistin resistance gene $m c r-1$ in Citrobacter freundii. Int J Antimicrob Agents. 2017;49:786-7. http://dx.doi.org/ 10.1016/j.ijantimicag.2017.04.004

7. Cannatelli A, Giani T, Antonelli A, Principe L, Luzzaro F, Rossolini GM. First detection of the $m c r-1$ colistin resistance gene in Escherichia coli in Italy. Antimicrob Agents Chemother. 2016;60:3257-8. http://dx.doi.org/10.1128/ AAC.00246-16

8. Monaco M, Giani T, Raffone M, Arena F, Garcia-Fernandez A, Pollini S, et al.; Network EuSCAPE-Italy. Colistin resistance superimposed to endemic carbapenem-resistant Klebsiella pneumoniae: a rapidly evolving problem in Italy, November 2013 to April 2014. Euro Surveill. 2014;19:20939. http://dx.doi.org/10.2807/1560-7917.ES2014.19.42.20939

9. Caselli E, D'Accolti M, Vandini A, Lanzoni L, Camerada MT, Coccagna $\mathrm{M}$, et al. Impact of a probiotic-based cleaning intervention on the microbiota ecosystem of the hospital surfaces: focus on the resistome remodulation. PLoS One. 2016;11:e0148857. http://dx.doi.org/10.1371/journal. pone. 0148857

10. Wand ME, Bock LJ, Bonney LC, Sutton JM. Mechanisms of increased resistance to chlorhexidine and cross-resistance to colistin following exposure of Klebsiella pneumoniae clinical isolates to chlorhexidine. Antimicrob Agents Chemother. 2016;61:e01162-16. http://dx.doi.org/10.1128/AAC.01162-16

Address for correspondence: Elisabetta Caselli, Universita Degli Studi di Ferrara Dipartimento di Scienze Mediche, Department of Medical Sciences, Section of Microbiology, via Borsari 46 Ferrara, Ferrara 44121 Italy; email: csb@unife.it 